\title{
Tecnologias Utilizadas no Ato de Estudar por Professores e Estudantes: um estudo descritivo*
}

\author{
HENRIETTE FERREIRA GOMES \\ Mestre em Educação/Doutoranda em Educação \\ Professora do Instituto de Ciência da Informação \\ Universidade Federal da Bahia (UFBA) \\ henriete@ufba.br \\ EULINA DA ROCHA LORDELO \\ Doutora em Psicologia \\ Professora da Faculdade de Filosofia e Ciência Humanas e do \\ Programa de Pós-graduação da Faculdade de Educação \\ Universidade Federal da Bahia \\ eulina@ufba.br
}

\begin{abstract}
Resumo
Estudo descritivo acerca da comunidade da Universidade Federal da Bahia (UFBA), cuja amostra foi composta pela Escola Politécnica (EP) e Faculdade de Filosofia e Ciências Humanas (FCH). Seu objetivo foi o de identificar, descrever e analisar como a oralidade, a escrita e outras tecnologias vêm sendo utilizadas na construção do conhecimento, junto a 103 docentes e 112 estudantes. A análise dos dados resultou da combinação das abordagens quantitativa e qualitativa. Os resultados demonstraram que o uso das diversas tecnologias vem ocorrendo mais intensamente, incluindo entre elas o computador e os materiais da Internet, nas etapas de acesso aos conteúdos e de debates/troca de informações, como uma estratégia voltada à organização de sínteses integradoras dos conteúdos estudados. A análise sugere que as práticas que exigem atenção concentrada parecem favorecer o uso da escrita e da leitura em papel, enquanto que as atividades de acesso e de debate, em atenção mais dispersiva, favorecem a articulação com as "novas tecnologias", indicando que estas são mais utilizadas quando permitem maior mobilidade e ação.

Palavras-chave: processamento da informação, práticas de estudo, ensino superior, tecnologias.

\footnotetext{
* Compõe parte dos resultados da pesquisa de mestrado a partir da qual foi produzida a tecnologias na educação universitária: utilização nas práticas de transferência e processamento da informação. 2000. 390p., il. Dissertação (Mestrado em Educação) Faculdade de Educação, Universidade Federal da Bahia, Salvador. Orientadora: Prof ${ }^{a}$. Dra. Eulina da Rocha Lordelo.
} dissertação referenciada nesta nota: GOMES, Henriette Ferreira. Oralidade, escrita e outras
\end{abstract}




\title{
Resumen
}

Estudio descriptivo sobre la comunidad de la Universidad Federal de Bahia (UFBA), cuya muestra fue compuesta por la Escuela Politécnica (EP) y la Facultad de Filosofía y Ciencias Humanas (FCH). Su objetivo fue identificar, describir y analizar como la oralidad, la escritura y otras tecnologías están siendo utilizadas en la construcción del conocimiento, junto a 103 docentes y 112 estudiantes. Los datos fueron analizados combinando los abordajes cuantitativo y cualitativo. Los resultados demonstraron que las diversas tecnologías se utilizan mas intensamente, incluyendo entre ellas al computador y los materiales de la Internet, en las etapas de acceso a los contenidos y de debates/intercambio de informaciones, como una estrategia vuelta a la organización de síntesis integradoras de los contenidos estudiados. El análisis sugiere que las prácticas que exigen una atención concentrada parecen favorecer el uso de la escritura y de la lectura en papel, mientras que las actividades de acceso y de debate, con atención más dispersa, favorecen la articulación con las "nuevas tecnologías", indicando que éstas son mas utilizadas cuando permiten mayor mobilidad y acción.

Palabras-clave: procesamiento de la información, prácticas de estudio, estudio universitário, tecnologías.

\begin{abstract}
Descriptive study focusing on UFBA's (Federal University of Bahia) community. The sample was composed by Polytechnics School and Faculty of Philosophy and Human Sciences. The objective was to identify, describe and analyze how orality, writing and other technologies are being used to construct knowledge. The information was obtained through interviews with 103 professors and 112 students. Data analysis was performed by combining quantitative and qualitative approaches. The results showed that the use of several technologies, including computers and materials taken from Internet, has been occurring more intensively at the moment of accessing the contents and debates or exchanging information as a strategy focusing on the organization of integrative syntheses of the contents studied. The analysis suggests that practices demanding focused attention seem to foster the use of paper versions when writing and reading, while the activities of accessing content and debating (using less focused attention) seem to foster an articulation with the "new technologies". This indicates that the subjects use the "new technologies" as long as they allow more mobility and action.
\end{abstract}

Key words: processing of information, study practices, higher education, technologies. 


\section{INTRODUÇÃO}

O processo de construção do conhecimento está relacionado à interligação de várias ações de acesso e processamento das informações, por meio das quais os sujeitos tomam contato com as informações, buscam compreendê-las e delas se apropriarem, incorporando-as ao seu próprio "acervo" de conhecimentos.

A existência dessas ações revela a posição ativa do sujeito no processo de transferência da informação, indicando que, a partir das ações de comunicação que viabilizam o acesso, ele realiza uma série de atividades que representam estratégias de apropriação do conhecimento comunicado, que podem ser caracterizadas como atividades de processamento, tendo como objetivo atingir as condições para a construção do conhecimento.

Quando o processamento das informações é analisado percebe-se que as diversas tecnologias da comunicação e informação apóiam a realização dessas atividades. Entretanto, tais tecnologias apenas são utilizadas na medida em que asseguram ao sujeito o poder de ação no ato de estudar, o que indica o caráter ativo da apropriação da informação que implica um processo de reconstrução do conhecimento por parte de quem estuda. O sujeito seleciona e adota somente aquelas tecnologias que realmente auxiliem suas ações no ato de estudar.

O saber se desenvolve a partir de um processo de comunicação, necessitando ainda que se estabeleçam prioridades, como também os canais de transferência que deverão mediar a ação comunicativa. Além disso, o desenvolvimento do saber exige também que o sujeito tome uma certa distância do primeiro contato com a informação, a fim de que possa aprofundar suas reflexões. Todas essas instâncias são importantes na construção do conhecimento, que representa um processo no qual, segundo Bruner (1998, p.77-78), enquanto a linguagem auxilia a seleção de pensamentos, os pensamentos selecionados, por sua vez, organizam a percepção e a ação que são executadas a partir da utilização de "ferramentas" e auxílios disponíveis na cultura, como idéias, teorias e conceitos fornecidos pela sociedade.

Quando o conhecimento comunicado (a informação) chega ao receptor ele não será absorvido automaticamente; o sujeito tem suas competências, um saber acumulado, experiências vividas que dialogarão com o texto recebido, mediando a interpretação e a compreensão. Isso representa uma cadeia de enquadramentos que interferem na construção do conhecimento. A interpretação é uma ação de composição e, ao mesmo tempo, de exclusão de conexões que ocorrem em função do momento e do espaço no qual se encontra o sujeito que interpreta. A recepção é sempre parcial e para tanto são feitas escolhas por meio das quais algo é eliminado. 
Assim, toda informação significa uma seleção e um confinamento (Bruner, 1998, p.270-300).

As diversas tecnologias auxiliam o processo de codificação do pensamento em palavras, possibilitando a objetivação, a sua materialização, bem como a interação com o pensamento de outros sujeitos. Essa interação convoca as tecnologias da comunicação e informação que permitem a análise, a elaboração e a interiorização do pensamento e do conhecimento construído. Dessa forma, Lévy (1993, p.152-161) justifica o conceito que adota de "tecnologias da inteligência" ou de "tecnologias intelectuais" (Lévy, 1999, p.11-18; p.157) ao se referir às tecnologias da comunicação e informação.

Nas ações comunicativas, por meio dos recursos tecnológicos, o homem pôde elaborar e verbalizar seu pensamento, apresentando-o exteriormente, assim como encontrou formas para alcançar e tentar compreender o pensamento de seus semelhantes, já que "A comunicação direta entre duas mentes é impossível, não só fisicamente como também psicologicamente" (Vygotsky, 1995, p.128). E dentre as tecnologias desenvolvidas, a linguagem foi a que gerou grande impacto em relação ao pensamento, por ter proporcionado as condições para uma reflexão orientada, capaz de realizar diferenciações, comparações e combinações, necessárias às ações de controle mais eficientes.

Na comunicação oral há um contexto específico no qual os interlocutores interagem diretamente instaurando uma dialogicidade que produzirá um texto resultante desse contato direto e da troca interativa de informações. Na oralidade ocorre o envolvimento entre os sujeitos dessa comunicação e destes com o próprio tema focalizado. A comunicação oral presencial, face a face, apenas se diferencia dos demais tipos de comunicação oral, em relação aos veículos midiáticos utilizados como o telefone, a televisão, o cinema etc., por meio dos quais se dá o enfraquecimento em maior ou menor grau da interatividade. Entretanto, as características essenciais da forma de realização da comunicação oral permanecem interferindo no processo de compartilhamento da informação. Como destaca Marcuschi (2001), o meio básico para a realização da comunicação oral é o som, sendo que neste tipo de comunicação os gestos, os movimentos, a entonação, a prosódia são variáveis importantes e fortemente presentes na composição do texto. Segundo o autor, a escrita pode ser neutralizada enquanto o som emitido na oralidade não é passível dessa neutralização, já que nele sempre estarão muito visíveis as marcas de quem produz a enunciação, permitindo assim a identificação das características do autor e até mesmo do planejamento estabelecido no processo de comunicação.

Na escrita há uma dependência do código verbal mais do que de pistas contextuais, da linguagem gestual, do universo semântico compartilhado entre os sujeitos da ação comunicativa e das regras de conversação vigentes (Kato, 1995, p.51-61). A escrita foi desenvolvida para registrar (materializar) o 
pensamento verbal, buscando a sua compactação sintática, em um discurso planejado mesmo que tal planejamento fique pouco evidenciado no enunciado.

Marcuschi (2001) defende que a escrita tem um caráter monológico enquanto a comunicação oral possui um caráter dialógico, no qual a percepção dos sinais lingüísticos, que evidenciam o planejamento do texto, tornam-se mais claros. Por outro lado, o autor concorda que na comunicação oral ocorre um envolvimento entre os interlocutores e destes com o tema em discussão, enquanto na comunicação escrita se dá um distanciamento, um enfraquecimento das marcas emocionais, como também daquelas referentes ao planejamento da comunicação.

Entretanto, Marcuschi (2001) ressalta que tais características diferenciadoras da oralidade e da escrita são insuficientes para uma associação da primeira a um estado caótico de produção e compreensão, e da escrita à simples representação da fala. Ambas favorecem a comunicação entre os sujeitos e são acionadas no processo de compreensão, no entanto, cada uma delas tem condições específicas de produção e correspondem a duas modalidades de representação.

No desenvolvimento do debate acerca dos atributos da oralidade e da escrita emerge a evidência da possibilidade de utilização articulada destes dois modos de representação, como tecnologias complementares ao favorecimento da comunicação e compreensão dos enunciados. Por exemplo, quando a comunicação escrita é articulada à oralidade secundária, como forma de complementar, reforçar e esclarecer a informação registrada, ocorre um crescimento do pensamento descontextualizado ${ }^{1}$ e a ampliação da simulação mental. Esse processo possibilita maior elaboração da representação e conseqüente fixação da informação gerada na memória de longo prazo, como também o desenvolvimento do potencial crítico e de crescimento da autonomia (Lévy, 1993, p.77-99).

A leitura, por sua vez, foi uma tecnologia criada para a análise e interpretação dos textos, com o objetivo de possibilitar a interiorização do pensamento materializado por meio da palavra escrita, em um processo de ampliação do próprio pensamento, envolvendo não apenas o estímulo visual, mas também outras informações não visíveis, que estão no universo cognitivo do leitor (Kato, 1995, p.82). Na apreensão do código escrito, por meio da percepção visual, o sujeito pode aperceber-se das lacunas do texto ou de sua própria interpretação, diante da "estabilidade" imposta à informação, que pode ser "manuseada" em movimentos de avanço e retorno às partes do texto, de acordo com as necessidades de cognição desse sujeito.

1 Pensamento elaborado a partir do manuseio da informação em um processo de desmembramento da mesma. 
Conforme Bougnoux (1994, p.98-99), na leitura do código escrito o sujeito tem o poder de girar em torno do enunciado que é fixo, desempenhando o papel de receptor ativo, contando com o olho que "(...) tem um poder separador muito superior ao ouvido que é menos analítico e mais sujeito aos valores da harmonia ou síntese. (...) A leitura permite que se volte atrás diferentemente da voz que é unidirecional".

Ao tentar conhecer algo, ao estudar, por meio de textos, o sujeito toma contato com as idéias de outros e com as suas próprias, em um esforço de análise que representa um movimento de reflexão intensa, que poderá levá-lo a uma compreensão e a uma auto-compreensão, devendo o assunto focalizado ser abordado, analisado, enfim, estudado com maior atenção.

O processamento da informação envolve aspectos ligados aos ambientes e modelos adotados na realização do ato de estudar, assim como às próprias atividades e tecnologias utilizadas. Segundo Marton e Salyo (1970 apud Sadler-Smith, 1999, p. 162), alguns desses aspectos podem, a depender do conhecimento a ser trabalhado, apresentar certas variações. Os padrões de aproximação com os conteúdos como formas utilizadas para o aprendizado podem ser de uma aproximação "aprofundada" ou "superficial".

O padrão usado para o aprofundamento da aproximação com os conteúdos aponta para uma ação individual, caracterizando-se por um esforço do sujeito para compreender criticamente o material analisado. De outra maneira, o padrão "superficial" caracteriza-se como um exame mais pontual, localizado, mais qualificado, que pode se adequar mais facilmente ao estudo em grupo. Entretanto, Sadler-Smith (1999, p.170-171), em seu estudo acerca de modelos de controle cognitivo, concluiu que o padrão utilizado para o aprofundamento da aproximação com o conteúdo varia de acordo com os objetivos do estudo, mais do que em relação a possíveis estilos cognitivos dos sujeitos, podendo, a depender do contexto, ser uma aproximação mais aprofundada ou superficial/estratégica.

Neste sentido, Silber (1998, p.64), avaliando o que a aproximação cognitiva representa para os projetos instrucionais, concluiu que a natureza do conhecimento a ser trabalhado também interfere na maneira como o sujeito desenvolve seu estudo. Ele propõe ainda que, quanto à natureza, o conhecimento pode ser declarativo, que "sabe o que/como é o mundo" e relativo a procedimentos que "sabe como fazer coisas no mundo". A depender do tipo de conhecimento trabalhado o padrão de aproximação ao conteúdo pode se alterar.

O sujeito que trabalha com o conhecimento declarativo, que explora intensamente as funções abstratas da linguagem, tende a adotar mais o padrão de aproximação mais aprofundada com o conteúdo, 
utilizando uma aproximação mais pontual em momentos estratégicos. De modo diferente, o sujeito que realiza estudos acerca de conhecimentos mais ligados aos procedimentos, tende a adotar mais constantemente o padrão de aproximação pontual, embora possa, a depender da situação, adotar o padrão de aproximação mais aprofundada (Silber, 1998, p.65).

Entretanto, embora as características do conhecimento trabalhado induzam a adoção de um ou outro padrão de aproximação, os sujeitos, em qualquer área do conhecimento, acabam por utilizar ambos os padrões em fases diferenciadas de apreensão do conhecimento e, em algum momento, acabam buscando a atenção concentrada.

No padrão usado para o aprofundamento da aproximação com os conteúdos, os sujeitos buscam exercer uma atenção mais concentrada que, conforme Del Nero (1997, p.295-306), representa um estado de vigília permanente, que mantém o cérebro constantemente preparado para realizar suas funções. Também Vygotsky e Luria (1996, p. 195) destacaram o papel da atenção na construção do conhecimento quando registraram que "(...) a atenção desempenha a função mais importante na vida do organismo. Essa função trata da organização do comportamento, com a criação de um determinado contexto, que prepara o homem para a percepção ou para a atividade".

Refletir a respeito de tais ações e o papel das tecnologias em apoio às mesmas torna-se importante, tanto para a área da informação quanto para a educação, já que a análise do processamento das informações no ato de estudar poderá auxiliar a compreensão das demandas e potencialidades que devem ser contempladas pelo planejamento das atividades didáticas e informacionais. Diante da diversidade de áreas do conhecimento que são trabalhadas no ensino universitário e à compreensão de que qualquer ação deve partir de uma reflexão acerca do que efetivamente vem ocorrendo, buscou-se analisar neste trabalho como vem sendo articulado o uso das tecnologias no processo de construção do conhecimento, nas práticas acadêmicas específicas das áreas das ciências exatas e das ciências humanas.

Dentro de uma investigação mais ampla, que teve como objetivo verificar o uso das diversas tecnologias da comunicação e informação no ensino universitário, buscou-se também verificar quais tecnologias auxiliam os processos cognitivos, apoiando a realização de atividades que funcionam como estratégias para o processamento das informações, estabelecendo comparações e verificando possíveis características que venham a orientar futuras ações de integração do uso das diversas tecnologias à educação universitária. 


\section{MÉTODO}

O trabalho caracterizou-se como um estudo descritivo, no qual foram articuladas as abordagens quantitativa e qualitativa, com o objetivo de realizar um levantamento para identificar, descrever e analisar as estratégias e as tecnologias utilizadas para o processamento de informações na construção do conhecimento.

\subsection{População e amostra}

A população correspondeu à comunidade de professores e alunos da Universidade Federal da Bahia (UFBA), cuja amostra foi definida a partir da escolha por intencionalidade de duas unidades de ensino inseridas nas áreas I (ciências exatas) e III (ciências humanas), por admitir-se a existência de diferenças quanto aos conteúdos informacionais trabalhados. Desta forma, foram selecionadas a Escola Politécnica (EP) e a Faculdade de Filosofia e Ciências Humanas (FCH).

Na sua composição, a amostra representou $50 \%$ dos professores em atividade nos cursos de graduação das duas unidades, correspondendo ao total de 103 docentes, sendo 53 casos da EP e 50 da FCH. Quanto aos alunos, a amostra correspondeu a quatro turmas, representando casos típicos escolhidos por intencionalidade e acessibilidade, sendo duas turmas de cada uma das unidades, correspondendo ao total de 112 estudantes, sendo 51 da EP e 61 da FCH. A seleção ocorreu a partir das informações fornecidas pelos professores por meio de questionários e entrevistas, utilizando-se como critérios de escolha o número de alunos, o uso mais ou menos intenso das "novas tecnologias" por seus professores e a disponibilidade de acesso aos estudantes em sala de aula.

\subsection{Instrumentos}

Foram utilizados questionários ${ }^{2}$ e folhas de registro cursivo para as anotações relativas às observações, impressões e relatos feitos durante as entrevistas com os docentes. O questionário focalizava, além de dados de identificação dos participantes, questões relativas à utilização das tecnologias da comunicação e informação, práticas de leitura, processamento das informações durante a leitura e no ato de estudar. Anteriormente à coleta dos dados, realizou-se um pré-teste, a partir do qual foram ajustados os questionários posteriormente aplicados entre os professores e os alunos.

2 Cópias dos instrumentos originais podem ser obtidas com a primeira autora. 


\subsection{Procedimentos de Análise dos Dados}

Os dados obtidos foram examinados para a elaboração das categorias de análise que, depois de estabelecidas, foram submetidas a um tratamento quantitativo, através do qual as freqüências e os percentuais foram calculados, como também comparados os grupos que compuseram a amostra, a partir da aplicação do teste do Qui-quadrado. Na realização dessa análise quantitativa foi utilizado o conjunto de programas do Statistical Package for Social Sciences (SPSS).

As informações coletadas a partir das questões abertas dos questionários, embora tenham sido tratadas em categorias para análise estatística, também foram analisadas qualitativamente pelo cruzamento com as informações obtidas nas entrevistas e registradas no diário de campo.

\section{RESULTADOS E DISCUSSÃO}

As atividades que auxiliam o processo de atenção, reflexão (análise) e síntese das informações levantadas, as quais estão relacionadas aos fluxos de pensamento, caracterizam-se como objetos de difícil abordagem, já que normalmente as pessoas não costumam refletir acerca dos passos e possíveis estratégias que desenvolvem no seu processo de construção de conhecimentos. Assim, deve-se registrar que a pretensão, neste caso, foi apenas a de buscar uma aproximação com esse complexo processo que é ao mesmo tempo coletivo, por ser gerado a partir de redes que conectam vários sujeitos ou grupos sociais, e individual, no qual cada sujeito, deliberadamente, desencadeia ações comunicativas na tentativa de entrar em contato com o que outros sujeitos já apreenderam a respeito do que ele está buscando conhecer.

As atividades de processamento das informações foram agrupadas em quatro grandes grupos, aplicados tanto aos professores (Tabela 1) quanto aos estudantes (Tabela 2): atividades de planejamento; de imersão e percepção do assunto em estudo; de reflexão (análise) e de síntese do que foi apreendido.

Entre os docentes, verifica-se que as atividades de planejamento são realizadas por auxiliarem a preparação do ato de estudar, facilitando a aproximação com o conteúdo, funcionando como um momento de exploração que permite uma introdução que se poderia chamar de primeira ordem. A definição dos objetivos já implica os passos iniciais pelos quais o sujeito tenta compreender o que o conduz a tal estudo, elaborando suas questões primeiras a respeito do que será estudado. Embora tal atividade 
tenha um caráter operacional, representa o processo inicial de reflexão, no qual ocorre um "diálogo interior" intensificando o debate entre as "vozes" que "habitam" o "universo interior", permitindo alguma clareza acerca do que se realizará, "aquecendo" e "exercitando" os movimentos mentais, que serão intensificados em etapas posteriores.

Conforme Bakhtin (1999, p.37-61, comentários do autor) o pensamento de caráter cognitivo é materializado com o apoio de conhecimentos anteriormente adquiridos, que ele compreende como um sistema ideológico de conhecimento, como também do psiquismo de cada sujeito e de seu aparato biológico que representam suas condições vitais e sociais. "Os processos de compreensão de todos os fenômenos ideológicos (um quadro, uma peça musical, um ritual ou um comportamento humano) não podem operar sem a participação do discurso interior." Dessa forma, a introspecção representa a orientação da atividade mental que se caracteriza como um "discurso interior", constituindo-se em um ato de compreensão.

Na mesma direção, a avaliação do tempo possibilita ao sujeito estabelecer os limites para a realização do seu estudo, permitindo que este se posicione melhor frente ao volume de informações disponíveis, sobre as quais deverá se "debruçar". E na elaboração de um roteiro temático esse exercício se intensifica, exigindo que o sujeito se esforce por perceber as ramificações e conexões importantes de seu problema de estudo. Alguns se referem a essa etapa como um "mergulho" um pouco mais profundo na elaboração de suas idéias iniciais, que tende a crescer, desencadeando as primeiras correlações com conhecimentos prévios.

Tais conexões e correlações passarão a uma etapa de aceleração durante a seleção e disponibilização das fontes de informação necessárias ao desenvolvimento do estudo, que também se caracteriza como uma atividade de planejamento, exigindo a tomada de decisões quanto à direção a ser seguida nesse processo. O sujeito é colocado diante da complexidade do seu tema, sendo convocado a alcançar maior clareza acerca dos aspectos de aprofundamento e estimulado a fazer associações e correlações mais determinantes, que funcionam como "bússolas" indicadoras dos pontos motivadores do empreendimento.

Percebe-se, portanto, que ao realizarem atividades de planejamento como: a definição dos objetivos/avaliação do tempo; a elaboração de um roteiro temático; a seleção e a disponibilização das fontes de informação, os sujeitos sentem que, de alguma maneira, elas auxiliam o desencadeamento de seus fluxos mentais, facilitando a construção de seus conhecimentos, embora não sejam realizadas por um grande número de docentes ou de estudantes.

Quanto às atividades que auxiliam no processo de imersão e percepção do assunto em estudo, destacaram-se a leitura integral com a 
produção de anotações $(55,4 \%)$ e a leitura seletiva do material, para identificação dos principais tópicos do texto $(36,9 \%)$; assim como para obter uma visão mais global a respeito do tema em questão $(24,3 \%)$.

É interessante observar como os sujeitos vinculam o ato de estudar à tecnologia da leitura, destacando-a como auxiliar no processo de imersão no assunto, assim como de sua percepção. Ocorre inclusive um desmembramento em relação às formas de leitura, sendo destacadas a leitura seletiva, a integral e até mesmo a releitura do próprio texto ou das anotações que são produzidas durante um primeiro contato com o texto $(13,6 \%)$. Outra parcela $(13,6 \%)$ indicou, ainda, um estilo diferenciado que é o da realização de leituras simultâneas.

A leitura integral, associada à produção de anotações, está ligada ao esforço de captura dos pontos mais importantes do texto lido. No registro desses pontos exercita-se a reflexão a partir do levantamento de questões, de dúvidas, de associações iniciais, de contraposições e até mesmo da tentativa de construir pequenos parágrafos que representem a compreensão obtida a partir do texto lido.

As anotações tanto são realizadas simultaneamente, quando os sujeitos tentam desenvolver sua reflexão de forma mais dirigida e sistemática em uma única leitura integral, quanto no processo de releitura do texto que foi, em um primeiro momento, lido de forma mais livre, buscando-se "sentir" o discurso do autor e desenvolver um contato inicial com o conteúdo temático, obtendo uma visão mais global. Nesse caso, os sujeitos buscam aprofundar a reflexão em uma segunda leitura, quando passam, de forma mais dirigida, pela produção de anotações, a capturar as idéias centrais e aquelas que surgem em suas mentes durante a releitura.

Quanto às atividades de reflexão para análise das informações, os professores apontaram, em maior número $(59,2 \%)$, que estabelecem comparações, correlações e associações com conhecimentos já adquiridos anteriormente, com fatos históricos e do cotidiano, bem como com assuntos correlatos e pontos de vista de outros autores e fontes.

Entre os docentes da $\mathrm{FCH}$ verificou-se também o hábito de elaboração de tabelas comparativas, quadros ou mapas, com a finalidade de buscar uma visualização mais abrangente das relações entre os conteúdos acessados e trabalhados durante a realização de seus estudos. Tais recursos possibilitariam uma disposição espacial, uma certa "geometrização" que facilita as correlações, comparações e associações necessárias à construção do conhecimento. 


\section{TABELA 1}

\section{DISTRIBUIÇÃO PERCENTUAL DOS PROFESSORES POR TIPO DE ATIVIDADES DE PROCESSAMENTO DAS INFORMAÇÕES DESENVOLVIDAS NO ATO DE ESTUDAR}

\begin{tabular}{|c|c|c|c|c|}
\hline \multirow[b]{2}{*}{ ATIVIDADES DESENVOLVIDAS } & \multicolumn{4}{|c|}{$\%$} \\
\hline & Total & EP & FCH & $\mathrm{p} \leq$ \\
\hline Atividades de planejamento & & & & \\
\hline Definição dos objetivos/avaliação do tempo & 18,4 & 17,0 & 20,0 & \\
\hline Elaboração de um roteiro temático & 12,6 & 17,0 & 8,0 & \\
\hline Seleção e disponibilização das fontes de informação & 24,3 & 32,1 & 16,0 & \\
\hline Atividades de imersão e percepção & & & & \\
\hline $\begin{array}{l}\text { Registrar deduções preliminares e esquemas idealizadores do } \\
\text { tema antes da realização de leituras }\end{array}$ & 10,7 & 9,4 & 12,0 & \\
\hline $\begin{array}{l}\text { Leitura seletiva para identificação dos tópicos fundamentais } \\
\text { do texto }\end{array}$ & 36,9 & 30,2 & 44,0 & \\
\hline Leitura integral com produção de anotações & 55,4 & 54,8 & 56,0 & \\
\hline $\begin{array}{l}\text { Releitura do texto ou leitura das anotações para aprofundar a } \\
\text { reflexão }\end{array}$ & 13,6 & 15,1 & 12,0 & \\
\hline Leituras simultâneas de vários textos & 13,6 & 17,0 & 10,0 & \\
\hline $\begin{array}{l}\text { Identificação de conceitos, fundamentos, bases filosóficas/ } \\
\text { epistemológicas/novas perspectivas (visão global) }\end{array}$ & 24,3 & 20,7 & 28,0 & \\
\hline $\begin{array}{l}\text { Atividades de reflexão (análise) } \\
\text { Refletir sobre os pontos relevantes do tema e seus diversos } \\
\text { aspectos }\end{array}$ & 38,8 & 45,3 & 32,0 & \\
\hline Estabelecer comparações, correlações e associações & 59,2 & 52,8 & 66,0 & \\
\hline Realizar simulações (mental/escrita) & 6,8 & 13,2 & 0 & 0,01 \\
\hline $\begin{array}{l}\text { Levantar questões, hipóteses e fazer generalizações / Realizar } \\
\text { verificações e observações empíricas }\end{array}$ & 24,3 & 30,1 & 18,0 & 0,01 \\
\hline Realizar interrupções & 12,6 & 9,5 & 16,0 & \\
\hline Atividades de síntese & & & & \\
\hline $\begin{array}{l}\text { Elaboração de resenha ou síntese crítica de leituras } \\
\text { simultâneas }\end{array}$ & 15,5 & 7,5 & 24,0 & 0,05 \\
\hline $\begin{array}{l}\text { Exposição oral em aulas, palestras etc. para organizar o } \\
\text { pensamento/idéias }\end{array}$ & 3,9 & 5,7 & 2,0 & \\
\hline Debater com outras pessoas & 6,8 & 7,5 & 6,0 & \\
\hline Total de casos & (103) & (53) & (50) & \\
\hline
\end{tabular}


Do total de docentes, 38,8\% registraram ainda que buscam refletir a respeito dos pontos relevantes do tema e seus diversos aspectos. Porém, a realização de simulações, tanto mental quanto escrita, foi apontada apenas entre os docentes da EP (13,2\%), representando uma diferença significativa $(p \leq 0,01)$ entre os dois grupos. Da mesma forma, a atividade de levantar questões, hipóteses, fazer generalizações, realizar observações empíricas e verificações práticas, procurando analisar as aplicações do que está sendo estudado, foi indicada por $30,1 \%$ dos docentes da EP, e por apenas $18,0 \%$ dos professores da $\mathrm{FCH}$, revelando outra diferença significativa $(\mathrm{p} \leq 0,01)$, o que, provavelmente, está relacionado às especificidades das duas áreas, já que o desenvolvimento de simulações e de cálculos está ligado às necessidades de visualização, de aplicação e de teste, muito próprias das ciências exatas.

Outro aspecto interessante refere-se à realização de interrupções durante o processo de estudo que, embora indicada por poucos e mais destacada na $\mathrm{FCH}$, cumpre um papel no desenvolvimento do estudo. Alguns sentem a necessidade de interromper o ato sistemático de estudar para que o pensamento ocorra mais livremente. Outros preferem interromper a reflexão direta para desenvolverem atividades manuais, físicas e de entretenimento, que funcionam como uma forma de liberação do pensamento, permitindo que a reflexão se torne mais livre. E, frente ao aparecimento de desdobramentos temáticos, alguns também costumam interromper momentaneamente o estudo para reflexão e registro do que poderá ser trabalhado em estudos futuros.

Quanto às atividades de síntese, a diferença significativa $(\mathrm{p} \leq 0,05)$ entre os dois grupos está na produção de resenha, indicada por $15,5 \%$ do total de casos (EP - 7,5\% e FCH - 24,0\%). Ainda dentre essas atividades, $3,9 \%$ dos professores revelaram sentir necessidade de expor oralmente os conhecimentos adquiridos por meio da explanação em aulas, palestras e eventos, quando podem falar e ouvir a respeito do tema. Tal atividade contribui para a organização do pensamento e das idéias, assim como o debate com outras pessoas, realizado por $6,8 \%$ dos docentes.

Em relação aos alunos, observa-se na Tabela 2 que, de uma forma geral, eles também apontaram aquelas atividades indicadas pelos docentes. Entre as atividades de planejamento destacaram a "seleção e a disponibilização das fontes de informação" $(16,1 \%)$, embora se tenha revelado, entre os dois grupos, uma diferença bastante significativa ( $\mathrm{p} \leq$ 0,001 ). Enquanto $27,9 \%$ dos alunos da $\mathrm{FCH}$ informaram que esta é uma atividade que auxilia o processo de estudar, apenas 2,0\% dos estudantes da EP registraram o mesmo.

Quanto às atividades de "imersão e percepção", os estudantes destacaram a leitura seletiva, que permite identificar os pontos mais 
importantes do texto $(51,8 \%)$ e também a leitura integral com a produção de anotações $(51,8 \%)$, assim como a identificação de conceitos, de fundamentos e das bases filosóficas, como forma de obter uma visão mais abrangente acerca do que está sendo estudado $(44,6 \%)$.

Ao apontarem as atividades que foram consideradas como de reflexão (análise), os alunos também destacaram o estabelecimento de comparações, correlações e associações (34,0\%). Entretanto, mostraram-se diferentes quanto à atividade de levantar questões e hipóteses, de realizar verificações e observações empíricas $(33,0 \%)$, indicada em proporções maiores entre os estudantes da EP (EP - 56,9\% e FCH - 13,1\%), apontando uma diferença bastante significativa entre eles $(\mathrm{p} \leq 0,001)$.

Outra diferença significativa $(\mathrm{p} \leq 0,05)$ entre os dois grupos corresponde à realização de simulações e o desenvolvimento de cálculos, que foi indicada apenas entre os estudantes da EP (7,8\%).

Quanto às atividades consideradas como de síntese os dois grupos informaram que buscam debater o assunto em estudo com outras pessoas $(15,2 \%)$ e elaboram resenhas $(11,6 \%)$, tentando construir uma visão própria a respeito do que foi lido e estudado.

Embora deva ser destacado que apenas uma pequena parcela dos docentes fez registro desta estratégia de síntese, comparativamente aos professores, os alunos não identificaram a exposição oral acerca do tema estudado como uma forma de organizar melhor o pensamento. Entretanto, pode-se ponderar que, para os primeiros, há uma possibilidade maior de compreender com clareza a validade desse procedimento em razão da própria prática docente, que torna mais visível a ativação dos "fluxos mentais" durante o processo de exposição e troca direta de informações, compreendendo-se "fluxos mentais" como os fluxos de oscilações e sincronizações que, segundo Del Nero (1997, p. 352), geram o potencial de ação dos sujeitos.

De acordo com o elenco de atividades indicadas por professores e alunos, o processamento das informações inicia-se a partir do momento no qual os sujeitos começam a planejar e preparar as condições para que o ato de estudar se aprofunde, sendo que a seleção e a disponibilização das fontes de informação iniciam o processo e favorecem a diminuição da ansiedade que muitas vezes bloqueia a ativação dos "fluxos mentais", também potencializando a capacidade de estabelecer relações importantes entre os diversos aspectos do problema ou até mesmo dos pontos de ligação com outras áreas do conhecimento. 
TABELA 2

DISTRIBUIÇÃO PERCENTUAL DOS ALUNOS POR TIPO DE ATIVIDADES DE PROCESSAMENTO DAS INFORMAÇÕES DESENVOLVIDAS NO ATO DE ESTUDAR

\begin{tabular}{|c|c|c|c|c|}
\hline \multirow[b]{2}{*}{ ATIVIDADES DESENVOLVIDAS } & \multicolumn{4}{|c|}{$\%$} \\
\hline & Total & EP & FCH & $\mathrm{p} \leq$ \\
\hline \multicolumn{5}{|l|}{ Atividades de planejamento } \\
\hline Definição dos objetivos/avaliação do tempo & 3,6 & 3,9 & 3,3 & \\
\hline Elaboração de um roteiro temático & 4,5 & 5,9 & 3,3 & \\
\hline Seleção e disponibilização das fontes de informação & 16,1 & 2,0 & 27,9 & 0,001 \\
\hline \multicolumn{5}{|l|}{ Atividades de imersão e percepção } \\
\hline $\begin{array}{l}\text { Registrar deduções preliminares e esquemas idealizadores do } \\
\text { tema antes da realização de leituras }\end{array}$ & 0,9 & 2,0 & 0 & \\
\hline $\begin{array}{l}\text { Leitura seletiva para identificação dos tópicos fundamentais } \\
\text { do texto }\end{array}$ & 51,8 & 52,9 & 50,8 & \\
\hline Leitura integral com produção de anotações & 51,8 & 50,9 & 52,5 & \\
\hline $\begin{array}{l}\text { Releitura do texto ou leitura das anotações para aprofundar a } \\
\text { reflexão }\end{array}$ & 26,8 & 25,5 & 27,9 & \\
\hline $\begin{array}{l}\text { Identificação de conceitos, fundamentos, bases filosóficas / } \\
\text { epistemológicas / novas perspectivas (visão global) }\end{array}$ & 44,6 & 41,2 & 47,6 & \\
\hline \multicolumn{5}{|l|}{ Atividades de reflexão (análise) } \\
\hline $\begin{array}{l}\text { Refletir sobre os pontos relevantes do tema e seus diversos } \\
\text { aspectos }\end{array}$ & 19,6 & 23,5 & 16,4 & \\
\hline Estabelecer comparações, correlações e associações & 34,0 & 33,4 & 34,5 & \\
\hline Realizar simulação (mental/escrita) & 3,6 & 7,8 & 0 & 0,05 \\
\hline $\begin{array}{l}\text { Levantar questões, hipóteses e fazer generalizações / Realizar } \\
\text { verificações observações empíricas }\end{array}$ & 33,0 & 56,9 & 13,1 & 0,001 \\
\hline Realizar interrupções & 1,8 & 0 & 3,3 & \\
\hline \multicolumn{5}{|l|}{ Atividades de síntese } \\
\hline Elaboração de resenha & 11,6 & 5,9 & 16,4 & \\
\hline Debater com outras pessoas & 15,2 & 15,7 & 14,8 & \\
\hline Total de casos & (112) & (51) & (61) & \\
\hline
\end{tabular}


Posteriormente, entra-se em uma fase de maior introspecção, por meio de atividades de imersão e percepção; de reflexão (análise) e de síntese, sendo que, para alguns, estas últimas podem ocorrer devido aos momentos de introspecção intercalados por outros de comunicação mais intensa com o "mundo exterior".

Dentre as estratégias que podem ser consideradas como próprias do processo de imersão e percepção do assunto destaca-se a leitura integral do texto e a anotação dos pensamentos e das idéias que surgem durante a leitura, assim como a própria compreensão que foi possível construir a partir dela. Nesse caso, as fontes impressas são as mais utilizadas, mesmo quando o acesso aos textos se dá pela Internet, já que estes são impressos para leitura em papel.

Há, de modo geral, um reconhecimento de que os meios eletrônicos permitem uma agilidade maior na atualização e na conexão com acervos informacionais distantes. Entretanto, ainda se mantém a tendência de, uma vez localizada a fonte, imprimi-la para uma leitura mais acurada e crítica, não por uma questão de hábito ou de resistência, mas porque a maioria dos sujeitos parece considerar a leitura intensa e sistematizada no computador mais difícil e cansativa.

Nesse sentido, Bawa (1997, p. 109-112), ao analisar os resultados de alguns estudos na área de ergonomia cognitiva ${ }^{3}$ destaca que estes têm avançado com a finalidade de apontar as necessidades de melhoramento das "novas tecnologias", como, por exemplo, no que diz respeito aos impactos na leitura. Segundo essa autora, durante a leitura realizada em papel, o córtex visual processa as informações dentro de pequenos intervalos entre atividades e repouso, enquanto na leitura realizada diretamente na tela do computador o olho processa as áreas nas quais não há texto, em razão das oscilações que são processadas pelo cérebro. Dessa forma, Bawa (1997, p.111) conclui que "Ler em uma tela de computador é literalmente um trabalho mais difícil que ler em uma folha de papel".

Por outro lado, mesmo realizando suas leituras em textos impressos, os sujeitos apontam para uma articulação importante entre os meios magnéticos/ eletrônicos e os impressos, que parecem se complementar para assegurar a construção dos sentidos a partir das informações neles registradas e por eles armazenadas e colocadas em circulação.

Essas considerações quanto às tecnologias da comunicação e informação permitem que se levante a hipótese de que a maioria das pessoas vincula o ato de estudar à leitura e à escrita. $\mathrm{O}$ ato de estudar

3 Ramo da ergonomia especializada no estudo do uso mais adequado de elementos do ambiente de trabalho que interagem com nossas mentes. 
parece depender do estabelecimento de uma linha, de uma diretriz que conduza, motive e até detenha os desvios, os "devaneios" que podem ocorrer com as conexões que se estabelecem durante a análise da informação. Escrever o que se pensa a respeito do que se lê, sinalizar pontos que se insinuam como importantes durante a leitura parecem facilitar o processo de atenção, de concentração e também o próprio desenvolvimento da reflexão ativa.

$\mathrm{O}$ ato de ler parece também estar relacionado, como defende Kato (1995, p.82), com informações não visíveis, que estão no universo cognitivo do leitor e que, integradas às informações visuais, geram as condições de se fazer previsões do que se encontra no texto lido, na busca de interpretá-lo melhor.

Assim, durante a leitura surgem questões que o leitor busca responder tendo como objetivo compreender um conteúdo; portanto, além de colocar a mente em contato com informações visuais, registradas em suportes externos de memória, também se faz conexões com aquelas informações "armazenadas" na própria memória, ao que a escrita traz sua contribuição.

Mais uma vez, então, constata-se que as tecnologias da escrita e da leitura estão articuladas, já que, ao ler um texto, independentemente do objetivo da leitura e da área do conhecimento com a qual trabalha, a maioria das pessoas produz anotações, notando-se apenas uma tendência mais acentuada entre aqueles que atuam na área das ciências humanas, o que também foi apontado por Silber (1998, p.64) que registrou ter verificado a existência de uma necessidade mais intensa da produção de notas, entre os que trabalham com um conhecimento mais declarativo.

A necessidade de produzir sublinhas ou anotações durante a realização de leituras e no ato de estudar corresponde, conforme Boruchovitch e Mercuri (1999, p.37-40), a uma estratégia que visa manter a atenção fixada no objeto de estudo, facilitando, de acordo com Marques (1999, p.59), a materialização das "funções abstratas da linguagem", a exteriorização do que estava no plano intersubjetivo para um suporte de registro, passível de ser examinado.

Esse diálogo interno e com o próprio texto que se exterioriza pela escrita facilita também o estabelecimento das correlações e comparações entre o que está sendo lido e o que já se conhece acerca do assunto, intensificando a comunicação intra e intersubjetiva. Nesse processo, a linguagem escrita funciona como um elo técnico que permite o fluxo dialógico entre os sujeitos, o que parece estar de acordo com o pensamento de Vygotsky (1995, p.128), de que não é possível uma comunicação direta entre as mentes. 
Durante o processamento das informações, o escrever significa marcar o pensamento no papel para que este seja analisado mais à frente. As anotações vão ressignificando as informações captadas do texto, vão desenhando o perfil de quem lê. O leitor deixa no texto suas marcas e será por meio delas que se acoplará àquele novo mundo de significados, o que representa o esforço particular de registro da gênese do seu próprio pensamento no contato com as idéias de outros sujeitos. Dessa forma, o leitor tem a possibilidade de aprender com seus próprios erros de interpretação, o que, conforme Dennett (1996, p.178), se tornou possível somente a partir da linguagem escrita, que é também uma ação de construção dos sentidos que auxilia a constituição da subjetividade, da internalização dos conhecimentos.

Na produção de anotações durante a leitura a maioria dos sujeitos prefere executá-las no papel, que parece assegurar uma interação mais estreita, simplificada e de maior familiaridade no registro mais imediato das idéias durante a leitura. Não obstante, o computador é articulado com maior tranqüilidade no processo de refinamento, facilitando muito a sistematização das anotações realizadas, oferecendo uma flexibilidade grande para possíveis conexões com anotações anteriores, o que estimula e agiliza a geração de textos, resumos ou resenhas.

Quando utilizado no ato de estudar, o computador cumpre mais a função de organizador de registros sistematizados, visando também a comunicação com o "mundo exterior" durante o processo de reflexão e maturação das idéias. Entretanto, este uso durante o ato de estudar inibe um pouco os fluxos mentais, por isso a maioria não o utiliza diretamente no processo de reflexão mais intensa e dirigida sob o estado de atenção concentrada. O que também pode ser corroborado pelos resultados de Oliveira (1999, p.104, comentários do autor), quando estes revelam que para os estudantes que participaram de sua pesquisa “(...) o texto produzido com o recurso convencional (papel e caneta) tem melhor estruturação de conteúdos, de outra parte, o texto digitado tem maior garantia de qualidade nos aspectos de apresentação (...)".

Assim, parece que, para a maioria, a utilização do computador é mais confortável em uma etapa posterior, quando a fase inicial da compreensão do texto, que representa um esforço mais intenso, já tenha sido vencida, indicando que os sujeitos buscam articular o uso dos recursos tecnológicos de forma a obter maior conforto e agilidade no ato de estudar, mas não os integram quando estes, de alguma forma, os inibem.

A utilização do computador possibilita que as informações consideradas importantes sejam armazenadas e conectadas entre si, além de facilitar a troca mais ágil dessas informações com outros sujeitos em casos de conexão com a Internet. Mesmo para aqueles que possuem 
alguma experiência quanto ao uso do computador, tais ações exigem que se percorra uma série de operações técnicas que tornam essa execução, durante o próprio momento da reflexão, uma tarefa ainda muito carregada de artificialidade, conflitando com a necessidade de familiarização com os aspectos do meio e de operações simplificadas que evitem qualquer apelo externo que desvie a atenção concentrada.

Conforme Antonello (1998, p.200-201), a escrita cursiva representa uma ação de estreita relação entre quem escreve e o texto, na qual o sujeito sente as palavras sendo geradas a partir do movimento de seu próprio corpo. Isso representa um conforto no ato de estudar, quando os sujeitos não desejam ações, movimentos ou interrupções que desviem seu processo de atenção concentrada ou que inibam sua imaginação.

Sem dúvida, o desenvolvimento cada vez maior do computador permitirá que ele se aproxime cada vez mais desse momento de grande introspecção que envolve $\mathrm{o}$ ato de estudar. Mas certamente serão necessários dispositivos simples e mais próximos da condição humana. A caneta (ou lápis) e o papel se acoplam perfeitamente, quase se transformando em extensões do corpo e, de alguma forma, também da mente humana. Para a maioria dos sujeitos eles não geram desconforto e artificializam ao mínimo o ambiente da reflexão. Isso parece ser o que faz com que a maioria ainda não utilize diretamente o computador para o registro das idéias e pensamentos que surgem no exato momento em que realizam suas leituras no ato de estudar.

As interrupções contribuem apenas quando não são casuais ou provocadas a partir de apelos externos. Para alguns sujeitos há momentos nos quais a interrupção é desejada, sendo realizada como parte do próprio processo de reflexão, funcionando como uma pausa estratégica que ocorre deliberadamente, resultando de um "chamado interno" do sujeito e não provocado a partir do "mundo exterior", o que fortalece a constatação de que normalmente os sujeitos necessitam de atenção concentrada para uma ação reflexiva mais sistematizada, podendo ser relacionada ao estado de vigília permanente que Del Nero (1997, p. 295-306) diz ser necessário para manter a atividade do cérebro e que, conforme Vygostsky e Luria (1996, p.195), apóia a organização do comportamento do sujeito preparando-o para a percepção e ação.

Aprofundando a análise dos pontos perceptíveis a partir da imersão no conteúdo estudado por meio da leitura e das anotações, a maioria dos sujeitos revelou desenvolver atividades estratégicas que ampliam a reflexão, como a realização de comparações, correlações e associações. Na sua execução a escrita surge novamente como auxiliar do processo de pensamento. 
Lendo o que foi anotado o sujeito aciona sua percepção visual e tenta tomar uma relativa distância do seu próprio pensar, no exato momento em que o pensamento se realiza, buscando sua coerência, compreensão e até mesmo a certificação do nível de absorção alcançada durante o estudo, demonstrando que a tomada de notas representa, conforme Adler e Van Doren (1974, p.94), um esforço para a realização de uma leitura mais analítica, na qual o ato de escrever e ler se interpenetram e se completam.

Nas atividades de reflexão (análise), ao fazer tais comparações, correlações e associações, busca-se contextualizar a informação, tentando dar a ela um sentido e verificar a sua coerência. Com o uso da linguagem os pensamentos são selecionados e, com o apoio das tecnologias e das representações já construídas, organizam a própria reflexão (Bruner, 1998, p.77-78).

Nesta etapa, a leitura e a escrita são articuladas na linguagem que apóia a mente no seu trabalho de integrar aos estímulos sensoriais as ações de intermediação do processamento das informações no ato de estudar. Assim, pode-se concluir que essas tecnologias dão suporte à linguagem na formação da teia conceptual que Del Nero (1997, p.341-354) afirma se estabelecer no córtex cerebral a partir das conexões que alteram nossos conhecimentos anteriores, produzindo nossas novas representações.

Nossas experiências, as interações que vivenciamos formam os "gabaritos" pelos quais processaremos a decodificação, isto é, a interpretação das informações que pudermos captar do "mundo exterior", representando assim um "espaço mental" no qual construímos nossas singularidades que, como defende Dahlet (1997, p.66-67), atuam na construção dos sentidos.

As comparações, correlações e associações permitem a estruturação de esquemas, mapas ou quadros, que tornam mais visíveis as estruturas estabelecidas mentalmente, facilitando a internalização, o que também ocorre com o levantamento de questões, hipóteses, aplicações e verificações práticas, demonstrando que a codificação da própria estrutura do pensamento desencadeia o processo de interpretação. E parece ser nesse sentido que Del Nero (1997, p.348) afirma existir uma relação entre a codificação e a interpretação enquanto fases da formação de memórias, nas quais a elaboração de esquemas representa uma estratégia auxiliar da construção dos sentidos, por delinear a estrutura sobre a qual emergirá a interpretação.

Assim, pode-se inferir que, ao confeccionar uma estrutura, o que se está produzindo em verdade é uma teia de relações na qual se quer enquadrar a nova informação. Conforme Del Nero (1997, p.348-349), "Esse é o mecanismo por excelência de que lança mão o cérebro para fixar 
lembranças". Para demonstrar o nascimento de uma estrutura de representação no cérebro, Del Nero (1997, p.349, observações do autor) apresenta o exemplo de uma possível formação da representação de um leão:

\footnotetext{
"Num primeiro momento, um conjunto de neurônios (módulo) associaria a visão de um leão (do primeiro leão de minha vida) com a palavra leão (que estaria noutro conjunto de neurônios). Com o tempo, a associaria a outros conjuntos de neurônios, como aquele que representa mamífero, leão da Metro, leão de chácara. Toda vez que se estabelecesse uma nova conexão, algumas ligações seriam reforçadas."
}

Nessa estrutura busca-se visualizar todas as interligações possíveis do tema trabalhado, o que parece estar, de alguma forma, ligado ao conceito de esquema construído por Rumelhart (apud Nöth, 1995, p.139), dentro da perspectiva das ciências cognitivas, de que o esquema corresponde a uma estrutura que, ao mesmo tempo, representa e organiza o conhecimento de maneira que ele seja internalizado e rememorado quando necessário.

Ao elaborar uma estrutura por meio de mapas, esquemas ou quadros contribui-se com a ativação do estabelecimento de um número maior de relações, sob o controle consciente da atenção concentrada, gerando a construção de uma representação, de uma interpretação que interliga organizadamente o novo conhecimento aos já internalizados, facilitando a compreensão e ao mesmo tempo a rememoração posterior. A rememoração é facilitada em função de que a informação estará ligada de forma distribuída a diversos pontos de conexão com outras informações contidas na memória.

Dessa forma, na tentativa de rememorar o sujeito contará com várias possibilidades de recuperação da informação diante da diversidade de pontos de acesso que foram gerados. Portanto, o hábito de construir tais estruturas, como facilitadoras da compreensão e da fixação de novos conteúdos na memória, também parece estar relacionado ao desmembramento das informações que Silber (1998) diz acontecer quando são "armazenadas" nos diversos "módulos" do cérebro.

$\mathrm{O}$ que apreendemos em um determinado momento de alguma forma se relaciona ao que já havíamos apreendido anteriormente, sendo este um processo semiótico, no qual os esquemas correspondem a uma teia de interconexões que foram estabelecidas pelo sujeito cognoscente. 
Por outro lado, a confecção dessas estruturas também revela um outro aspecto que contribui para o processo de reflexão e assimilação dos conteúdos que é a possibilidade de transformar as conexões feitas mentalmente em códigos visuais que facilitam a análise mais acurada.

Todas as atividades voltadas para o desenvolvimento do processo de reflexão (análise) são executadas pelo sujeito a partir de seus sentidos, de sua base cultural e com o apoio das tecnologias, o que, conforme Bougnoux (1994, p.249, p.270-300), representa uma cadeia de enquadramentos, na qual a interpretação reflete uma recepção sempre parcial, indicando que o conhecimento construído resulta de um processo de seleção.

Porém, ao desenvolver suas estratégias de estudo, o sujeito tem como objetivo a construção de uma visão crítica em relação ao objeto de análise e a apropriação de um novo conhecimento, alcançando uma visão capaz de sintetizar os pontos mais relevantes do assunto estudado.

Entretanto, em relação às atividades de síntese constatou-se que são as de mais difícil identificação por parte dos sujeitos, já que apenas algumas das estratégias registradas podem ser assim consideradas. Para alguns estas atividades parecem ser compreendidas mais como conseqüência natural do processo de reflexão, mas outros têm clareza de que, ao elaborarem uma resenha, aprofundam a absorção do conteúdo estudado; em razão de que ao desenvolverem essa atividade organizam melhor seus pensamentos, registrando inclusive o "diálogo" que estabeleceram com outros autores durante a reflexão a respeito do texto lido, o que favorece a compreensão e a sedimentação do conhecimento na memória, já que, conforme Bakhtin, 1981 (apud Wertsch, Smolka, 1994, p.127), compreender qualquer conteúdo enunciado passa por compreender as relações que nele e a partir dele se estabelecem com outras enunciações.

\section{CONCLUSÃO}

Entre as estratégias de processamento das informações e suas tecnologias auxiliares, as principais transformações na construção do conhecimento que, até o momento, parecem advir das "novas tecnologias" dizem respeito às mudanças quanto ao conjunto de ações que são desenvolvidas no processo de transferência das informações, com a intensa circulação das idéias, atualização e troca de informações, que tornam a comunicação mais eficiente e dinâmica, potencializando o debate e imprimindo um novo ritmo entre a construção, a estabilidade e a reconstrução dos conhecimentos. 
As inovações mais evidentes estão relacionadas à velocidade com a qual temos de renovar nossos níveis de acoplamento aos objetos de estudo, em permanente alteração, diante das amplas possibilidades de conexões que se pode estabelecer com aspectos agora mais propensos a serem identificados. Entretanto, o conhecimento é o resultado da articulação dos estágios de acesso e de debate das idéias, mas também de reconstrução e reorganização mental das informações, que envolvem o processamento dessas informações. E, do ponto de vista das etapas de imersão e reflexão aprofundada, cujos resultados obtidos indicaram que ocupam um lugar central dentre as estratégias de processamento, não vem ocorrendo uma integração das "novas tecnologias" às mais tradicionais porque em tais etapas os sujeitos voltam-se para seu "mundo interior" na tentativa de acompanhar seus próprios fluxos de pensamento, procurando manter o cérebro em estado de vigília e no comando consciente das operações mentais, que levarão à percepção e ao processo criativo, preferindo assim tecnologias de operações menos complexas, com as quais já estejam familiarizados.

Embora as "novas tecnologias" incorporem a leitura e a escrita, estas ainda são realizadas, por meio desses recursos, com um nível maior de artificialidade e desgaste em razão da fadiga física e psicológica que ainda causam. A produção de textos no computador é uma inovação recente, em processo de aperfeiçoamento e de disseminação na sociedade e que mistura aspectos que se poderia chamar de primeira e de segunda ordem na construção do conhecimento, como a organização sintática do texto com a própria reflexão e geração das idéias, causando desconforto e dispersão na elaboração do pensamento diante da interpretação de um texto.

Do mesmo modo que, ao longo do tempo, a escrita e a oralidade se integraram e passaram a ser utilizadas em um processo de articulação quase "transparente", será necessário um tempo de experimentação para que as "novas tecnologias" sejam integradas com o mesmo nível de adaptação. Ainda não é possível dizer se essa integração, para o desenvolvimento do ato de estudar, se manterá apenas nas etapas identificadas neste estudo, mas pode-se afirmar que os sujeitos incorporam as tecnologias às suas práticas somente na proporção em que estas lhes assegurem a possibilidade de ação e de controle sobre o ato de estudar. Além disso, o próprio uso que atualmente se faz das diversas tecnologias e a trajetória de integração entre oralidade e escrita apontam para uma tendência de utilização que caracterizam as tecnologias da comunicação e informação como tecnologias complementares. 


\section{REFERÊNCIAS BIBLIOGRÁFICAS}

ADLER, M. J.; VAN DOREN, C. A arte de ler. Tradução de José Laurenio de Melo. Ed. rev. atual. Rio de Janeiro: Agir, 1974. 393p. Título original: How to read a book.

ANTONELLO, P. Ordinauteur: a tela e a página. In: ROCHA, João Cezar de Castro (org.). Interseções: a materialidade da comunicação. Rio de Janeiro: Imago; EDUERJ, 1998. 366p., il. p. 197-211. [Coletânea dos trabalhos apresentados no Colóquio UERJ, 6., 29-31 ago. 1995]

BAKHTIN, M. M. The dialogic imagination: four essays by M. M. Bakhtin. Editado por M. Holquist. Tradução de C. Emerson e M. Holquist. Austin: University of Texas Press, 1981. Apud WERTSCH, SMOLKA, 1994.

Marxismo e filosofia da linguagem: problemas fundamentais do método sociológico na ciência da linguagem. Tradução de Michel Lahud e Yara F. Vieira. 9.ed. São Paulo: Hucitec, 1999. 196p.

BAWA, Joanna. Computador e saúde: manual do usuário: problemas, prevenção e cura. Tradução de Eduardo Farias. São Paulo: Summus, 1997. 230p., il. Título original: The computer user's health handbook.

BORUCHOVITCH, E; MERCURI, E. A importância do sublinhar como estratégia de estudo de textos. Tecnologia educacional, [S.1.], v.28, n.144, p.37-40, jan./fev./mar. 1999.

BOUGNOUX, D. Introdução às ciências da informação e da comunicação. Petrópolis: Vozes, 1994. 336p.

BRUNER, J. Realidade mental, mundos possíveis. Tradução de Marcos A. G. Domingues. Porto Alegre: Artes Médicas, 1998. 211p., il. Título original: Actual minds, possible worlds.

DAHLET, P. Dialogização enunciativa e paisagens do sujeito. In: BRAIT, Beth (org.). Bakhtin, dialogismo e construção do sentido. Campinas: Editora da UNICAMP, 1997. 385p. p. 59-84.

DEL NERO, H. S. O sítio da mente: pensamento, emoção e vontade no cérebro humano. São Paulo: Collegium Cognitivo, 1997. 510p., il.

DENNETT, D. Linguagem e inteligência. In: KHALFA, Jean (org.). A natureza da inteligência: uma visão interdisciplinar. Tradução de Luiz Paulo Rouanet. São 
Paulo: Editora UNESP, Cambridge University, 1996. 212p. , il. cap. 7, p.163-179. Título original: What is intelligence?

KATO, M. O aprendizado da leitura. 4. ed. São Paulo: Martins Fontes, 1995. 144p. (Texto e Linguagem)

LÉVY, P. Cibercultura. Tradução de Carlos Irineu da Costa. São Paulo: Ed. 34, 1999. 260p. (coleção TRANS). Título original: Cyberculture.

As tecnologias da inteligência: o futuro do pensamento na era da informática. Tradução de Carlos Irineu da Costa. Rio de Janeiro: Editora 34, 1993. 203p., il. (Coleção TRANS). Título original: Les technologies de l'intelligence.

MARCUSCHI, L. A. Da fala para a escrita: atividades de retextualização. 3. ed. São Paulo: Cortez, 2001. 133p.

MARQUES, M. O. A escola no computador: linguagens rearticuladas, educação outra. Ijuí: Ed. UNIJUÍ, 1999. 216p.

MARTON, F.; SALJO, R. On qualitative differences in learning: I. outcome and process. British Journal of Educational Psychology, [S.1.], n. 46, [p.4-21], 1970. Apud SADLER-SMITH, 1999.

NÖTH, W. Panorama da semiótica: de Platão a Peirce. São Paulo: Annablume, 1995. 149p. [Coleção E, 3]

OLIVEIRA, J. M. A. de. Escrevendo com o computador na sala de aula: uma análise de redações escolares. 1999. 123f., il. Dissertação (Mestrado em Educação) Faculdade de Educação, Universidade Federal da Bahia, Salvador.

RUMELHART, D. E. Schemata: the building blocks of cognition. In: SPIRO, R. J.; BRUCE, B. C.; BREWER, W. F. (org.). Theoretical issues in reading comprehension. Hillsdale: Lawrence Eribaum, [s.d.]. p.33-58. Apud NÖTH, 1995.

SADLER-SMITH, E. Intuition-analysis style and approaches to studying. Educational Studies, [S.1.], v.25, n.2, p.159-173, July 1999.

SILBER, K. H. The cognitive approach to training developmen: a practitioner's assessment. Educational technology Research and Development, [S.1.], v.46, n.4, p.58-72, 1998. 
VYGOTSKY, L. S. Pensamento e linguagem. Tradução de Jeferson L. Camargo. São Paulo: Martins Fontes, 1995. 135p., il. Título original: Thought and language.

VYGOTSKY, L. S.; LURIA, A R. Estudos sobre a história do comportamento: o macaco, o primitivo e a criança. Tradução de Lólio Lourenço de Oliveira. Porto Alegre: Artes Médicas, 1996. 252p., il. Título original: Studies on the history of behavior: ape, primitive, and child.

WERTSCH, J. V.; SMOLKA, A. L. B. Continuando o diálogo: Vygotsky, Bakhtin e Lotman. In: DANIELS, Harry (org.). Vygotsky em foco: pressupostos e desdobramentos. São Paulo: Papirus, 1994. 296p. cap. 4, p.121-149.

Recebido em: outubro 2002 Aprovado para publicação em: junho 2004 